\title{
Incorporating learning into theories of parsing
}

\author{
Evan Kidd \\ The Australian National University, \\ ARC Centre of Excellence for the Dynamics of Language
}

In their target article, Phillips and Ehrenhofer (2015; P\&E) present a sketch of how concepts and methods from adult language processing could be used to illuminate first and second language acquisition. This is by no means the first attempt to find common ground between fields that often work independently of each other (e.g., for L1: Fodor, 1998a, 1998b; Frazier \& De Villiers, 1990; O’Grady, 2005; Trueswell \& Gleitman, 2004, for L1 \& L2: MacWhinney \& Bates, 1989). Regardless, one broad aim of psycholinguistics should be to integrate sub-disciplines, and in this sense the article is a welcome addition to the literature. In this vein, $\mathrm{P} \& \mathrm{E}$ argue that adult psycholinguistics can provide important and novel insights into the acquisition of grammars. In this commentary I concentrate on the converse of this argument: how insights from language acquisition can provide equally important contributions to adult psycholinguistics. My broad thesis is that processing considerations not only constrain learning, but that learning constrains the developing parser, such that we can see the footprints of acquisition in the end-state processing system. Due to space limitations I restrict my discussion to L1 acquisition.

\section{Language processing and language acquisition}

The language acquisition process, as conceptualised within any theoretical tradition, concerns both information processing and its product (i.e., mental representations). Thus it is self-evident that the leaner's input is filtered through the processing system, and that the manner in which this occurs affects learning. A majority of L1 acquisition research has concentrated on the outcome of this process, tracking developmental change (or lack thereof) in knowledge states over the course of months and years to infer developmental mechanisms. The advantage of studying (on-line) processing in acquisition is that we can determine how children process their input in real time, thus identifying the sources of information 
to which children attend across development, giving us a more complete picture of the acquisition process and a more integrated account of both language acquisition and language processing.

$\mathrm{P} \& \mathrm{E}$ concentrate on syntactic processing. They commit to a formal approach to language, whereby parsers implement grammars as described by (Chomskyan) linguistic theory, augmented by a small number of processing heuristics that negotiate structural ambiguities. While it could be argued that this approach does not easily link processing to acquisition (Kidd, 2004), there are explicit proposals about how this could in principle occur (e.g., Fodor, 1998b; Sakas \& Fodor, 2012). One limitation, as I see it, is that the focus on the implementation of a formal modular grammar that is minimally affected by experience across development (beyond parameter setting) does not fully capture the developmental course of acquisition and how the processing system is implicated in and affected by this process. In what follows I discuss how a more fully integrated account of learning and processing can yield important insights into both fields. I focus my discussion on a topic familiar to developmental and adult psycholinguists: restrictive relative clauses.

\section{Processing effects as learning effects}

The comprehension of relative clauses (RCs) has received considerable attention in the adult processing literature. With very few exceptions, subject RCs like (1) are easier to process than object RCs like (2).

(1) The lawyer [that questioned the defendant] was aggressive.

(2) The defendant [that the lawyer questioned] was aggressive.

In those languages where the subject-object asymmetry exists in adult on-line comprehension, it also exists in acquisition (e.g., Kidd \& Bavin, 2002). Following $\mathrm{P} \& \mathrm{E}$, this continuity between $\mathrm{L} 1$ acquisition and adult processing could be attributed to processing difficulties associated with object RCs, as described in theories of adult parsing (e.g., Gibson, 1998). However, explaining children's difficulty in acquisition by appealing to theories of adult processing removes one important variable in language acquisition: development. Integrating developmental and adult psycholinguistics necessitates that we look at how learning influences the shape of the adult parser.

Several converging lines of research suggest a role for learning in the processing of RCs. Firstly, corpus studies in several languages reveal that subject and object RCs have very different distributional properties (e.g., Diessel, 2009; Fox \& Thompson, 1990; Kidd, Brandt, Lieven, \& Tomasello, 2007). Specifically, whereas 
subject relatives are more likely to have animate head nouns, object RCs almost always contain inanimate heads. Additionally, object RCs typically have discourseold RC subjects, and, in English, rarely contain a relative pronoun. As such, children are more likely to hear object RCs like (3) rather than the ones on which they are typically tested, like (2).

(3) The film I saw last night.

These distributional properties of RCs stem from functional properties of language (Du Bois, 1987): (i) subjects are typically human and animate, whereas objects are typically inanimate, and (ii) in conversation subjects tend to be discourse-old (for a variationist account of relative pronoun use see Fox \& Thompson, 2007). Children rapidly seize upon these distributional patterns (Diessel \& Tomasello, 2000; Diessel, 2009), which neatly predict children's linguistic behaviour in experiments (Kidd et al., 2007; Brandt, Kidd, Lieven, \& Tomasello, 2009). This suggests that a mechanism that is sensitive to distributional frequency is important in acquisition (Ambridge, Kidd, Rowland \& Theakston, 2015).

One crucial point about this research is that when children are tested on object RCs that conform to constraints on object RC formation, the subject-object asymmetry disappears and in some circumstances reverses, reflecting the fact that, in some languages, object RCs are typically more frequent than subject RCs in spoken language (e.g., Roland, Dick, \& Elman, 2007). The same result occurs in studies of adult processing (Mak, Vonk, Schriefers, 2002; Reali \& Christiansen, 2007; Traxler, Williams, Blonzis, \& Morris, 2005; Weckerly \& Kutas, 1999).

Taking into account the full range of distributional facts and their effects on L1 acquisition and adult processing demands that we consider the source of these effects. Following P\&E (Level 2: Learning as Processing), are they attributable to properties of the parsing mechanism and therefore not particularly revealing about grammatical development, or do they reveal deeper insights into the relationship between processing and acquisition? I would like to suggest the latter.

In the Production-Distribution-Comprehension (PCD) model of language, MacDonald (2013) argues that production biases shape the distribution of forms in language. Language learners implicitly acquire these statistical regularities from their input, which subsequently guide comprehension (and further learning). These production biases neatly capture the distributional facts concerning subject and object RCs (e.g., use conceptually prominent nouns first, re-use recently processed structures, see MacDonald, 2013, p. 11). The approach is computationally instantiated in connectionist models of language. For instance, Chang, Dell, and Bock's (2006) connectionist model of sentence production makes predictions about comprehension based on the production biases it learns over the course of acquisition. Fitz, Chang, and Christiansen (2011) successfully extended the model 
to $\mathrm{RC}$ acquisition. In these models there is no clear-cut distinction between acquisition and processing; knowledge is acquired through the business of processing and predicting the nature of the input (see Dell \& Chang, 2014).

The PDC and connectionist instantiations of the approach (see also Christiansen \& MacDonald, 2009) therefore identify a key role for learning in processing. Distributional regularities like those characteristic of RCs are acquired as parsing routines and are implemented online. The subject-object asymmetry evident in experiments that test sentences such as (1) and (2) is explained by the fact that the animate head noun in (2) biases the prediction of a subject RC, based on its greater likelihood given the Animate NP-that fragment (Gennari \& MacDonald, 2008, 2009), not due to a universal preference to relativise on subject NPs (a discourse new subject RC noun further violates another constraint on processing object RCs). The asymmetry can be ultimately traced back to the processing mechanisms supporting acquisition. The system's sensitivity to input is evident even in adulthood, where structural priming effects are explained as implicit learning (see Chang et al., 2006), and in the case of RCs neutralise the subject-object asymmetry (Hutton \& Kidd, 2011; Wells, Christiansen, Race, Acheson, \& MacDonald, 2009).

\section{Concluding remarks}

First language acquisition necessarily implicates processing. On the flipside, the adult linguistic system is the product of language acquisition, and so we need theoretical models that span both fields. P\&E do an admirable job in summarising much of the research conducted to date, as well as identifying important priorities for future research (e.g., reanalysis). However, their approach overlooks the potentially important role of acquisition in explaining processing effects. Models like the PDC and Chang et al's (2006) production model provide good examples of theories that go some way to meeting this challenge. Inevitably, there is a lot more work to be done. It is encouraging to note that processing, broadly construed, has become a research focus in developmental psycholinguistics (e.g., Fernald, Perfors, \& Marchman, 2006; Junge \& Cutler, 2014; Snedeker, 2013). We can therefore expect greater theoretical development in the years to come. 


\section{References}

Ambridge, B., Kidd, E., Rowland, C., \& Theakston, A. (2015). The ubiquity of frequency effects in first language acquisition. Journal of Child Language, 42, 239-273.

DOI: 10.1017/S030500091400049X

Brandt, S., Kidd, E., Lieven, E., \& Tomasello, M. (2009). The discourse bases of relativization: An investigation of young German and English-speaking children's comprehension of relative clauses. Cognitive Linguistics, 20, 539-570. DOI: 10.1515/COGL.2009.024

Chang, F., Dell, G.S., \& Bock, K. (2006). Becoming syntactic. Psychological Review, 113, 234272. DOI: $10.1037 / 0033-295 X .113 .2 .234$

Christiansen, M.H., \& MacDonald, M.C. (2009). A usage-based approach to recursion in sentence processing. Language Learning, 59, 126-161. DOI: 10.1111/j.1467-9922.2009.00538.x

Dell, G.S., \& Chang, F. (2014). The P-Chain: Relating sentence production and its disorders to comprehension and acquisition. Philosophical Transactions of the Royal Society B, 369, 20120394, 1471-2970

Diessel, H. (2009). On the role of frequency and similarity in the acquisition of subject and nonsubject relative clauses. In T. Givón \& M. Shibatani (Eds.), Syntactic complexity: Diachrony, acquisition, neurocognition, evolution (pp.251-276). Amsterdam: John Benjamins.

DOI: $10.1075 /$ tsl.85.11ont

Diessel, H., \& Tomasello, M. (2000). The development of relative clauses in spontaneous child speech. Cognitive Linguistics, 11, 131-151.

Du Bois, J.W. (1987) The discourse basis of ergativity. Language, 63, 805-855.

DOI: $10.2307 / 415719$

Fernald, A., Perfors, A., \& Marchman, V.A. (2006). Picking up speed in understanding: Speech processing efficiency and vocabulary growth across the second year. Developmental Psychology, 42, 98-116. DOI: 10.1037/0012-1649.42.1.98

Fitz, H., Chang, F., \& Christiansen, M.H. (2011). A connectionist account of the acquisition and processing of relative clauses. In E. Kidd (Ed.), The acquisition of relative clauses: Processing, typology, and function (Vol 8, pp. 39-60). Amsterdam: John Benjamins.

DOI: 10.1075/tilar.8.04fit

Fodor, J.D. (1998a). Learning to parse? Journal of Psycholinguistic Research, 27, 285-319. DOI: $10.1023 / \mathrm{A}: 1023258301588$

Fodor, J.D. (1998b). Parsing to learn. Journal of Psycholinguistic Research, 27, 339-374. DOI: $10.1023 / \mathrm{A}: 1023255705029$

Fox, B., \& Thompson, S. (1990). A discourse explanation of the grammar of relative clauses in English conversation. Language, 66, 856-870. DOI: 10.2307/414888

Fox, B., \& Thompson, S. (2007). Relative clauses in English conversation: Relativizers, frequency, and the notion of construction. Studies in Language, 31, 293-326.

DOI: $10.1075 /$ sl.31.2.03fox

Frazier, L., \& de Villiers, J. (Eds.) (1990). Language processing and language acquisition. Dordrecht: Kluwer. DOI: 10.1007/978-94-011-3808-6

Gennari, S., \& MacDonald, M.C. (2008). Semantic indeterminacy in object relative clauses. Journal of Memory and Language, 58, 161-187. DOI: 10.1016/j.jml.2007.07.004

Gennari, S., \& MacDonald, M.C. (2009). Linking production and comprehension processes: The case of relative clauses. Cognition, 111, 1-23. DOI: 10.1016/j.cognition.2008.12.006 
Gibson, E. (1998). Linguistic complexity: Locality of syntactic dependencies. Cognition, 68, 1-76. DOI: 10.1016/S0010-0277(98)00034-1

Hutton, J., \& Kidd, E. (2011). Structural priming in comprehension of relative clauses: In search of a frequency by regularity interaction. In E. Kidd (Ed.), The acquisition of relative clauses: typology, processing, and function (pp. 227-242). Amsterdam: John Benjamins.

DOI: 10.1075/tilar.8.11hut

Junge, C., \& Cutler, A. (2014). Early word recognition and later language skills. Brain Sciences, 4, 532-559. DOI: 10.3390/brainsci4040532

Kidd, E. (2004). Grammars, parsers, and language acquisition. Journal of Child Language, 31, 480-483. DOI: $10.1017 /$ S0305000904006117

Kidd, E., \& Bavin, E.L. (2002). English-speaking children's understanding of relative clauses: Evidence for general-cognitive and language-specific constraints on development. Journal of Psycholinguistic Research, 31, 599-617. DOI: 10.1023/A:1021265021141

Kidd, E., Brandt, S., Lieven, E., \& Tomasello, M. (2007). Object relatives made easy: A crosslinguistic comparison of the constraints influencing young children's processing of relative clauses. Language and Cognitive Processes, 22, 860-897. DOI: 10.1080/01690960601155284

MacDonald, M.C. (2013). How language production shapes language form and comprehension. Frontiers in Psychology, 4(Article 226), 1-16.

MacWhinney, B., \& Bates, E. (Eds.) (1989). The crosslinguistic study of sentence processing. Cambridge, UK: Cambridge University Press.

Mak, W.M., Vonk, W., \& Schriefers, H. (2002). The influence of animacy on relative clause processing. Journal of Memory and Language, 47, 50-68. DOI: 10.1006/jmla.2001.2837

O'Grady, W. (2005). Syntactic carpentry: An emergentist approach to syntax. Mahwah, NJ: Erlbaum.

Phillips, C., \& Ehrenhofer, L. (2015). The role of language processing in language acquisition. Linguistic Approaches to Bilingualism, 5, 409-453.

Reali, F., \& Christiansen, M.H. (2007). Processing of relative clauses is made easier by frequency of occurrence. Journal of Memory and Language, 57, 1-23. DOI: 10.1016/j.jml.2006.08.014

Roland, D., Dick, F., \& Elman, J. (2007). Frequency of basic English grammatical structures: A corpus analysis. Journal of Memory and Language, 57, 348-379.

DOI: 10.1016/j.jml.2007.03.002

Sakas, W.G., \& Fodor, J.D. (2012). Disambiguating syntactic triggers. Language Acquisition, 19, 83-143. DOI: 10.1080/10489223.2012.660553

Snedeker, J. (2013). Children's sentence processing. In R. van Gompel (Ed.), Sentence processing (pp. 189-220). New York, New York: Psychology Press.

Traxler, M.J., Williams, R.S., Blozis, S.A., \& Morris, R.K. (2005). Working memory, animacy, and verb class in the processing of relative clauses. Journal of Memory and Language, 53, 204-224. DOI: 10.1016/j.jml.2005.02.010

Trueswell, J.C., \& Gleitman, L. (2004). Children's eye-movements during listening: developmental evidence for a constraint-based theory of sentence processing. In J.M. Henderson \& F. Ferreira (Eds.), Interface of vision, action, and language (pp. 319-346). NY: Psychology Press.

Weckerly, J., \& Kutas, M. (1999). An electrophysiological analysis of animacy effects in the processing of object relative sentences. Psychophysiology, 36, 599-570.

DOI: $10.1111 / 1469-8986.3650559$

Wells, J.B., Christiansen, M.H., Race, D.S., Acheson, D.J., \& MacDonald, M.C. (2009). Experience and sentence comprehension: Statistical learning and relative clause comprehension. Cognitive Psychology, 58, 250-271. DOI: 10.1016/j.cogpsych.2008.08.002 


\section{Author's address}

\section{Evan Kidd}

Research School of Psychology

The Australian National University

ARC Centre of Excellence for the Dynamics of Language

The Australian National University

Acton, 2601, ACT

AUSTRALIA

evan.kidd@anu.edu.au 